doi:10.12662/2359-618xregea.v10i3.p48-61.2021

ARTIGOS

\section{AS METODOLOGIAS ATIVAS NA PERCEPÇÃO DOS DOCENTES E DISCENTES DO CURSO DE ADMINISTRAÇÃO E ECONOMIA DA UAST/UFRPE}

\section{ACTIVE METHODOLOGIES IN THE PERCEPTION OF TEACHERS AND DISCENTS OF THE MANAGEMENT AND ECONOMY COURSE AT UAST / UFRPE}

Renan Silva Ferreira renansilvaferreirax@gmail.com Mestre em Mestrado em Administração e Desenvolvimento Rural. Docente da Universidade Federal Rural de Pernambuco. Serra Talhada - PE - BR.

Maria Rickaely Andrade rickaelyandrade10@gmail.com Graduanda em Administração pela Universidade Federal Rural de Pernambuco. Serra Talhada - PE - BR.

\section{RESUMO}

Este estudo objetiva analisar a percepção dos docentes e discentes acerca das metodologias ativas utilizadas nos cursos de Administração e Economia da Unidade Acadêmica de Serra Talhada - Universidade Federal Rural de Pernambuco (UAST/UFRPE). Ele foi realizado por meio de uma pesquisa bibliográfica (Base Scielo) e híbrida, mediante utilização de dois questionários on-line, estruturados em 16 perguntas, contendo uma amostra com 15 docentes respondentes, e outro com 12 perguntas, contendo uma amostra de 93 discentes respondentes, dos cursos estudados. Dessa forma, é possível verificar que, majoritariamente, existem professores formados em Administração, com 2 a 19 anos de atuação, e em ambas as atuações, existem aqueles que conhecem as metodologias ativas, mas entendem que elas ainda não são facilmente compreendidas pelos discentes. Os estudos dirigidos, sala de aula invertida, seminários e debates são provenientes de interesse dos docentes e apontados como os métodos que mais contribuem para a aprendizagem individual e coletiva, principalmente, pela dificuldade em disciplinas com predominância em cálculos.

Palavras-chave: metodologias ativas; docentes; discentes; administração; economia.

\section{ABSTRACT}

This study aims to analyze the perception of professors and students about the active methodologies used in the Administration and Economics courses of the Academic Unit of Serra Talhada - Federal Rural University of Pernambuco (UAST / UFRPE). It was conducted through a bibliographic research (Base Scielo)
\end{abstract}


and hybrid, through the use of two online questionnaires, structured with 16 questions, containing a sample with 15 respondent professors, and another with 12 questions, containing a sample of 93 respondent students, from the courses studied. Thus, it is possible to verify, for the most part, there are professors with a degree in Administration, with 2 to 19 years of experience, and both, there are those who know about the active methodologies, but understand that they are notyet easily understood by the students. The directed studies, inverted classroom, seminars and debates come from the interest of the professors and are pointed out as the methods that most contribute to the individual and collective learning, mainly, by the difficulty in disciplines with predominance in calculations.

Keywords: active methodologies; teachers; students; management; economic.

\section{INTRODUÇÃO}

Os diferentes métodos educacionais utilizados para promover uma melhor aprendizagem dos estudantes têm sido postos bastante em prática atualmente, isso ocorre devido à procura por estratégias que busquem meios para melhor fixação do conteúdo. Assim, as metodologias ativas são ferramentas que visam promover a autonomia e a participação dos estudantes de forma integral, aplicadas a partir da realidade de cada instituição de ensino e adaptadas às diferentes formas individuais ou coletivas de conhecimento.

O estudo em questão pretende analisar a percepção dos métodos utilizados pelos docentes em seus planos de aula, bem como a percepção dos discentes sobre as táticas utilizadas pelos seus professores e professoras, nos cursos de Administração e Economia da Unidade Acadêmica de Serra Talhada; além disso, irá refletir sobre os procedimentos que proporcionam maior nível de aprendizado, na garantia do ensino público, gratuito, de qualidade e na redução das dificuldades encontradas nesse processo. Estudo esse que se evidencia como relevante, pois aborda uma percepção de um período atípico e também auxilia na construção de ciclos de controle e avaliação de perspectivas futuras desses feedbacks para novos planejamentos, interesses e compreensões didáticas, entendendo como se dão as aplicações dessas estratégias gradativamente, especialmente por meio do auxílio das tecnologias, contribuindo, assim, para o melhor desempenho da comunidade acadêmica e relacionamento com a sociedade mediante a sua atuação.

Dessa forma, os métodos a serem investigados serão as duas percepções acerca das metodologias ativas que se configuram como uma nova maneira de transmissão e construção do conhecimento, fazendo os estudantes protagonistas de sua própria aprendizagem, seja ela individual, seja geral.

Nessa perspectiva, o objetivo do presente estudo é analisar a percepção dos discentes e docentes sobre as metodologias ativas utilizadas nos cursos de Administração e Economia da Unidade Acadêmica de Serra Talhada - Universidade Federal Rural de Pernambuco (UAST/UFRPE).

Nos próximos tópicos, será abordada a revisão da literatura sobre as metodologias ativas e sua aplicação. Em seguida, serão discorridos os procedimentos metodológicos de natureza híbrida, do tipo exploratória e descritiva com a aplicação de questionários para os atores envolvidos; logo após, será apresentada a análise dos resultados e a discussão e, por conseguinte, as considerações finais do trabalho e as referências bibliográficas utilizadas.

\section{REFERENCIAL TEÓRICO}

A expansão das universidades adaptadas à nova era digital vem transformando a maneira de participação dos docentes e discentes no ensino e aprendizagem. A classe universitária enfrenta mudanças com salas de aulas cada vez maiores e diversificadas, demandas do governo, e do mercado de trabalho que espera profissionais com força de trabalho imediata. Dessa 
forma, a tecnologia precisa trabalhar para os docentes e discentes de forma a absorver, ao máximo, seus benefícios (BATES, 2017).

A mudança cultural no ambiente escolar será maciça quando a sala de aula tradicional centrada na figura do professor, como único detentor do conhecimento, passar a ser um ambiente mais inovador, flexível e focado na aprendizagem do aluno. E, nesse novo ambiente, o professor se torna mais importante, pois a tecnologia possibilita mais liberdade e flexibilidade, aumentando a eficiência de sua prática pedagógica em sua área de ensino (PEREIRA, 2017).

Drucker (2000 apud MASETTO, 2004, p. 200): "afirma que, nos próximos cinquenta anos, as escolas e as universidades sofrerão mudanças e inovações mais drásticas que nos seus últimos trezentos anos, quando se organizaram em torno da mídia impressa". As novas tecnologias têm gerado novas demandas sociais, exigindo das instituições de ensino respostas cada vez mais inovadoras.

As tecnologias possibilitam um ambiente participativo entre ensinar e aprender, possibilitando uma comunicação mais aberta, podendo ser elaborada individualmente ou em grupo. "É importante educar para a autonomia, para que cada um encontre o seu próprio ritmo de aprendizagem e, ao mesmo tempo, é importante educar para a cooperação, para aprender em grupo, para intercambiar ideias, participar de projetos, realizar pesquisas em conjunto." (MORAN, 1998, p. 125).

Nesse cenário, as Tecnologias Digitais de Informação e Comunicação (TDIC), que designam um conjunto de diferentes mídias, proporcionaram importantes mudanças na educação. Atualmente, a discussão não é mais se deve ou não utilizar a tecnologia como ferramenta educacional, pois é uma realidade, já que se debate a utilização de forma eficiente e proveitosa dessas ferramentas (LOBO; MAIA, 2015).

No entanto, o professor necessita ficar atento se a utilização das tecnologias está ocorrendo de forma a proporcionar integração, e não como forma de distração ou fuga, ma- joritariamente, a tendência é para a dispersão rápida, diante de tantas conexões possíveis de busca. O que, na perspectiva do aluno, torna-se mais atraente acessar, de forma rápida, coisas novas do que comparar e analisar seus pontos de convergência e divergência. Moran (1998, p. 126) diz que: "Aprender é passar da incerteza a uma certeza provisória que dá lugar a novas descobertas e a novas sínteses".

Um dos eixos das mudanças na educação passa pela transformação da educação em um processo de comunicação autêntica, aberta, entre professores e alunos, principalmente, mas também incluindo administradores e a comunidade. Só aprendemos profundamente dentro de um contexto comunicacional participativo, interativo, vivencial (MORAN, 1998, p. 125).

No cenário de transformação que o sistema educacional vem passando, Masetto (2004) defende a substituição de metodologias tradicionais assentadas em aulas expositivas, por metodologias pautadas no estímulo de o aluno buscar e entender suas formas de aprendizagem. Substituindo a figura do professor que ministra aulas, para o mediador pedagógico, que fomenta o diálogo de forma acessível e encoraja os alunos a serem mais participativos nas aulas.

À medida que as metodologias ativas ganham força de implementação no sistema educacional, este passa a exigir dos docentes outras posturas quanto à aprendizagem em sala de aula, já que contribui com a formação dos profissionais que irão atuar na nova Sociedade do Conhecimento ${ }^{1}$. Logo, é necessário, por parte dos docentes, desenvolver práticas de criticidade mediante tantas informações, pensamento próprio e apresentá-las aos alunos juntamente com posicionamento de outros autores (MASETTO, 2009).

1 De forma condensada, é pautada na valorização do direito de acesso à informação, às tecnologias de informação e comunicação e à educação de forma igualitária (DZIEKANIAK; ROVER, 2013). 
O processo de aprendizagem da nova Sociedade do Conhecimento, segundo Masetto (2009, p. 7) está pautado nas seguintes perguntas que os docentes devem-se questionar antes de elaborar suas metodologias de ensino:

$\mathrm{O}$ que meu aluno do $3^{\circ}$ semestre do curso de graduação em administração precisa aprender nesta ou naquela disciplina para que se forme um profissional conforme definido pelo Projeto Político Pedagógico do curso? Como fazer para que meu aluno descubra a relevância e a importância da matéria que estou lecionando e se envolva com seu processo de aprendizagem? Como fazer para que o aluno venha estudar para aprender e não só para tirar uma nota?

Para Dewey (1959 apud BACICH, 2018, p. 17): "Não podemos dizer que ensinamos algo se ninguém aprendeu, assim como não podemos dizer que vendemos se ninguém comprou". Então, podemos distinguir duas maneiras de análise para "ensinar", mesmo que o professor tenha transmitido todos os conteúdos previstos no seu plano de ensino, se os alunos não aprenderam, na perspectiva de Dewey, ele não ensinou. Para o autor, o ensino está centralizado na aprendizagem do aluno, que não deve permanecer de forma receptora passiva (BACICH, 2018).

Quanto aos alunos do ensino superior, a maioria são jovens que ainda estão desenvolvendo autoconhecimento, entendendo a atuação da profissão escolhida, posição política e descobrindo sua rede de socialização com colegas de curso ou, até mesmo, de trabalho. Desse modo, é fundamental um professor que os oriente na realização de uma formação profissional competente, que estejam abertos ao diálogo, e os estimule no desenvolvimento de uma carreira de sucesso (MASETTO, 2009).

Sendo que "[...] não é possível oferecer a mesma aula a todos, porque as pessoas são diferentes em diferentes aspectos, aprendem em ritmos, tempos e formas diferentes, aumenta ainda mais a necessidade de aprofundar o olhar para as metodologias ativas" (BACICH, 2018, p. 4). Logo, é necessário um olhar atento a essas especificidades nas formas de aprendizagem, para garantir que todos realmente aprendam.

Diante desse cenário, é fundamental a discussão sobre o uso das metodologias ativas. Esse conjunto de novas práticas ativas de ensino surgiram no século XX, oferecendo maior liberdade e autonomia, tornando o aluno protagonista de sua própria aprendizagem. Diferente do modelo passivo em que o professor é o protagonista da aprendizagem e o aluno, o receptor. Freire (1996) destaca que tanto o professor, quanto o aluno são transformados no processo de ação educativa e aprendem, ao mesmo, tempo que ensinam.

A aprendizagem de forma ativa tem o objetivo de incentivar diversos processos cognitivos do aluno, sua interação com os colegas de sala e a aproximação com problemas reais do cotidiano. Dessa forma, "pode-se afirmar que aprender de forma ativa envolve a atitude e a capacidade mental do aluno em buscar, processar, entender, pensar, elaborar e anunciar, de modo personalizado, o que aprendeu" (FERRARINI; SAHEB; TORRES, 2019 p. 5). Existem diversas estratégias para atingir o modelo ativo de aprendizagem, sendo as principais, apresentadas a seguir.

Aprendizagem Baseada em Problemas (ABP) - Problem Based Learning (PBL), segundo Pereira (2017), foram desenvolvidas, inicialmente, para o curso de Medicina na década de 1960. Nessa metodologia, o professor assume a posição de orientador, e os alunos serão investigadores/pesquisadores, divididos em pequenos grupos. São apresentados aos alunos problemas os quais deverão estudar e apresentar os resultados encontrados. "O professor é o facilitador do processo de aprendizado, do trabalho em grupo e da comunicação entre alunos" (FERRARINI, SAHEB, TORRES, 2019, p. 12).

Aprendizagem baseada em Projetos (ABP) - Project-Based Learning (P BL), para Pereira (2017), possui a finalidade de estimular 
os alunos a fazer indagações e buscar as resoluções por meio do gerenciamento de tempo, definição de objetivos, assumindo responsabilidades e gerindo a autoavaliação. Assim, essa metodologia incorporada às tecnologias digitais atuais e próprias do século XXI modificam os modelos de estudo, otimizando o tempo e as formas de processar e buscar soluções para os problemas estudados (FERRARINI; SAHEB; TORRES, 2019).

Aprendizagem baseada em Games e Gamificação - Game-Based Learning (GBL), segundo Pereira (2017), essa metodologia é baseada na aprendizagem por jogos, em que se deduzem regras e manipulam-se sistemas complexos. São utilizados para melhorar a capacidade de raciocínio dos alunos em sala de aula.

Estudo de caso selecionado para esta pesquisa é uma metodologia que apresenta casos reais, como forma de preparar os alunos para buscar soluções de problemas do cotidiano. Envolve capacidades de interpretação, análise, elaboração de argumentos e podem ser beneficiadas por meio do uso das tecnologias. O professor é o mediador dos debates, elaborando estudos teóricos e estratégias, e ao aluno cabe organizar seus argumentos para os debates em sala (FERRARINI; SAHEB; TORRES, 2019).

Avaliação por Pares - Peer Instruction criada na Universidade de Harvard (EUA), para o curso/disciplina de física introdutória no final dos anos 1990. Essa metodologia busca, por meio da aplicação de questionários, fomentar os debates em sala, entre outros aspectos e nuances teóricas que ajudariam a contextualizar tal método. Geralmente, para esse método, são necessárias salas de aulas com acesso à internet e com equipamento de projeções (FERRARINI; SAHEB; TORRES, 2019).

Sala de Aula Invertida - Flipped Classroom, na perspectiva de Pereira (2017) nessa metodologia, o aluno assume o papel de protagonista de sua aprendizagem de forma bem mais acentuada, e as atividades são or- ganizadas em presenciais e a distância. Esse modelo, segundo Valente (2014), é utilizado no blended learning no qual os alunos têm acesso ao conteúdo antes do início das aulas, sendo a aula o lugar de debates e aplicação das metodologias ABP's, GBL, estudo de casos e possibilita maximizar os pontos positivos do ensino presencial e da EaD. E para Ferrarini; Saheb e Torres (2019) não se configuram como metodologias ativas, pois apenas invertem o modelo tradicional de aulas, já que o professor deixa de dar aulas presenciais para ensinar por videoaulas, sendo, ainda, o detentor do conhecimento e os alunos, receptores.

Pode-se concluir que a sala de aula invertida, na forma apresentada, é uma metodologia tradicional, a qual se inverteu a técnica relativa aos papéis do professor e dos alunos, apenas, ao beneficiar-se das possibilidades das tecnologias digitais, o que é muito distante do conceito de metodologia e de aprendizagem ativa, embora seja um avanço considerável, pois passa a focar a aprendizagem do aluno nos momentos presenciais com o professor e não o ensino (FERRARINI; SAHEB; TORRES, 2019, p. 21).

Para Pereira (2017, p. 8), "a aprendizagem ativa não é a cura para todos os problemas educacionais". Nesse sentido, as metodologias ativas discutidas são um caminho para o desenvolvimento de ensino e aprendizagem ativo, pautado no diálogo acessível em sala de aula, e um olhar atento para as diferentes maneiras de cada aluno aprender, sendo fundamental a interação de professores e alunos na aplicação das diversas metodologias ativas, com o auxílio das Tecnologias Digitais de Informação e Comunicação (TDIC), para ,assim, promover resultados positivos na educação da nova Sociedade do Conhecimento.

E para Silva e Leonardo (2020, p. 145) "o professor, por meio das metodologias inovadoras decorrentes da utilização da tecnolo- 
gia, poderá melhor executar sua área de conteúdo, proporcionando, assim, um ensino e aprendizagem transformador e compatível ao século XXI". Dessa forma, a adaptação das novas metodologias de ensino ocorre de forma gradual, visto que é necessária uma avaliação contínua sobre os pontos positivos e as dificuldades a serem enfrentadas, tanto pelos professores, quanto pelos estudantes.

\section{PROCEDIMENTOS METODOLÓ- GICOS}

Este estudo classifica-se como do tipo exploratório e descritivo com uma abordagem híbrida - natureza qualitativa e quantitativa, sendo realizada uma pesquisa bibliográfica na base de dados da Scielo por meio de livros, artigos, periódicos e sites para obter maior embasamento teórico sobre a temática.

As técnicas escolhidas supracitadas repousam de uma forma mais adequada ao trabalho, pois, conforme Gil (2010), Richardson (2012) e Yin (2005), é possível classificar as pesquisas em exploratória, que proporciona maior conhecimento e familiaridade com o fenômeno ou problema; a pesquisa descriti$v a$, que descreve as características de determinado fenômeno ou problema, e a pesquisa explicativa, que identifica os elementos que contribuem para a ocorrência do fenômeno,e os explica, inclusive, na aplicação de questionário que possibilita traçar perfis e identificações de variáveis e fatores que ajudam a interpretar as percepções.

Os cursos selecionados para a aplicação da pesquisa foram Administração e Economia, pela proximidade de parcerias e, por serem os cursos que atuam dentro das ciências sociais aplicadas no caso da UAST. O curso de Administração contém 271 alunos e 29 professores, e, no curso de Economia, há 255 alunos e cerca de 25 professores. A relevância estatística deste recorte pode ser observada na visualização do quantitativo, apesar das limitações e da coleta de dados.

Definiu-se a aplicação de dois questio- nários estruturados mediante plataforma do Google Forms, sendo um formulário on-line com 16 perguntas sobre o uso das metodologias ativas no ensino superior, direcionadas aos docentes, em que houve 16 respondentes e se caracterizam como amostra docente deste estudo. O segundo formulário, somando 12 perguntas sobre a aprendizagem por meio das metodologias ativas no ensino superior, direcionado aos discentes dos cursos já mencionados, compreendendo em 93 respondentes.

Nessa perspectiva, o estudo exploratório "tem como objetivo conhecer a variável de estudo tal como se apresentam seu significado e o contexto em que ela se insere." (PIOVESAN; TEMPORINI, 1995, p. 321). Assim, esse método auxilia no conhecimento das percepções sobre as metodologias ativas, no quadro da UAST/UFRPE.

Em relação ao estudo descritivo, "são muitos os tipos de gráficos e tabelas e também medidas de síntese como porcentagens, índices e médias" (REIS; REIS, 2002, p. 5). Com isso, os dados coletados podem ser mais bem apresentados e interpretados pelos leitores, permitindo uma melhor compreensão visual dos resultados do presente estudo.

"A pesquisa qualitativa é entendida por alguns autores como uma "expressão genérica". Isso significa, por um lado, que ela compreende atividades ou investigação que podem ser denominadas específicas" (OLIVEIRA, 2011, p. 24). E "na pesquisa quantitativa, a determinação da composição e do tamanho da amostra é um processo no qual a estatística tornou-se o meio principal" (OLIVEIRA, 2011, p. 26). Dessa forma, optou-se por uma abordagem qualitativa e quantitativa, em que os resultados foram estruturados a partir de gráficos e textos.

Os dados da pesquisa foram coletados entre janeiro e março de 2020, utilizando docentes e discentes dos cursos de Administração e Economia da UAST/UFRPE. E, após a coleta, os dados foram estruturados em gráficos e apresentados, de forma descritiva, nos textos, que estão localizados nos resultados. 


\section{APRESENTAÇÃO DOS RESULTA- DOS E DISCUSSÃO}

Diante da pesquisa realizada com 15 professores e 93 alunos da UFRPE-UAST, ambos dos cursos de Bacharelado em Administração e Bacharelado em Ciências Econômicas, tornou-se possível elaborar uma série de análises em forma de gráficos e análises livres, as quais estão distribuídas abaixo, sobre a percepção das metodologias ativas e sua influência em sala de aula.

No gráfico 1, buscou-se entender quantos dos docentes e discentes têm conhecimento acerca das metodologias ativas. Diante do agrupamento dos dados, podemos ver que 14 professores afirmaram conhecer tais metodologias, representando $93,3 \%$, enquanto 1 professor afirmou não conhecer, representando $6,7 \%$. Com isso, podemos dizer que há um aumento na probabilidade de os professores optarem por utilizar tais metodologias.

Ainda mais, é possível observar que 56 estudantes afirmaram conhecer as metodologias ativas o que corresponde a 60,22\%. Ao passo que 37 respondentes afirmaram não conhecer tais metodologias, correspondendo a $39,78 \%$. Dessa forma, esses resultados apontam que ambos os professores e alunos conhecem as metodologias ativas, o que pode estimular a mudança cultural no ambiente escolar (PEREIRA, 2017).

Gráfico 1 - Percepção dos docentes e discentes

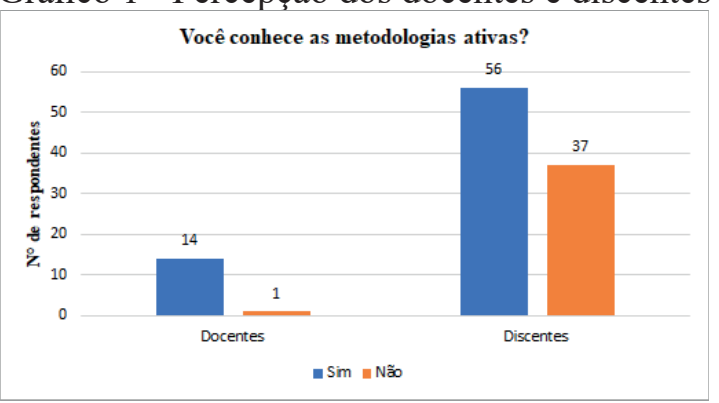

Fonte: elaborado pelos autores (2020).

O gráfico 2 foi elaborado com o intuito de entender quantos professores utilizam alguma das metodologias ativas no seu plano de ensino. Como pode ser observado abaixo, 13 professores afirmaram que utilizam tais metodologias que representam $86,7 \%$. Seguido dos 2 professores que afirmaram não utilizar tais metodologias, representando 13,3\%. Assim, o conhecimento e a utilização desses mecanismos por parte dos docentes da unidade acadêmica corroboram a visão de Moran (1998) de fomentar o estímulo no aprendizado em grupo, intercâmbio de ideias, participar em projetos e realizar pesquisas em conjunto.

Gráfico 2 - Utilização das metodologias ativas

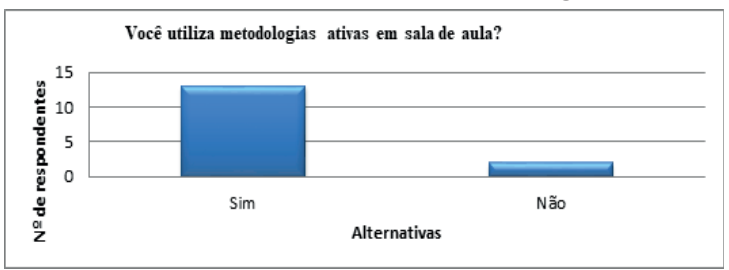

Fonte: elaborado pelos autores (2020).

No gráfico 3, buscou-se diagnosticar quais são os desafios enfrentados pelos docentes, quanto à aplicação das metodologias ativas em sala. Pode-se observar que seis professores afirmaram que é a falta de entendimento acerca de tais metodologias - estando na cor verde representa $40 \%$, seguido dos 4 professores que afirmaram ter dificuldade por falta de participação dos alunos - indicado na cor vermelha - representa 26,7\%. Assim, houve também três professores que afirmaram ser por falta de recursos disponibilizados pela instituição - cor azul - representando $20 \%$. Um professor afirmou ser por falta de compreensão dos alunos - cor lilás - representando $6,7 \%$, e outro professor que afirmou ser por baixo nível de interesse do aluno - cor azul e representa $6,7 \%$.

Dessa forma, tais resultados indicam a necessidade de maior discussão dos mecanismos de aplicação e compreensão dessas ferramentas, para, assim, proporcionar maior aprendizagem. Conforme defende Masetto (2004), a substituição de metodologias tradicionais assentadas em aulas expositivas, para aulas mais participativas e com maior participação dos discentes. 
Gráfico 3 - Desafios quanto à aplicação das metodologias ativas por parte dos docentes

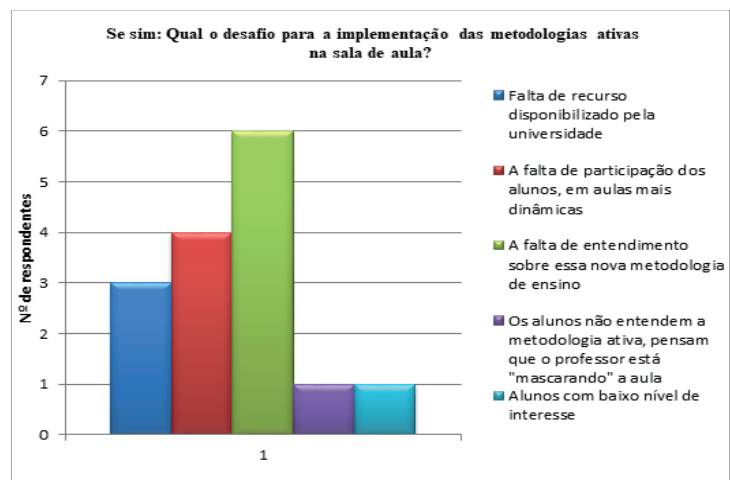

Fonte: elaborado pelos autores (2020).

No gráfico 4, buscou-se identificar a preferência dos discentes e quais metodologias ativas eles apreendem mais. Entre os métodos, percebemos que o mais votado foi o "debate", possuindo 62 marcações que correspondem a 66,66\%. Seguido dos "projetos" com 46 marcações e 49,46\%. Logo após, os "seminários" com 38 marcações e $40,86 \%$ e os "trabalhos em grupo" com 32 marcações e $34,40 \%$. O restante dos métodos, que são visitas técnicas, exercícios, exercícios práticos, gincana e artigos ou resumos tiveram somente uma marcação, ficando com $1,07 \%$ do total. Assim, é possível observar as especificidades nas formas de aprendizagem individual, discutidas por Bacich (2018), tendo em vista que o conjunto delas é o que garante, de fato, que todos aprendam.

Gráfico 4 - Preferência dos discentes quanto às metodologias aplicadas em sala

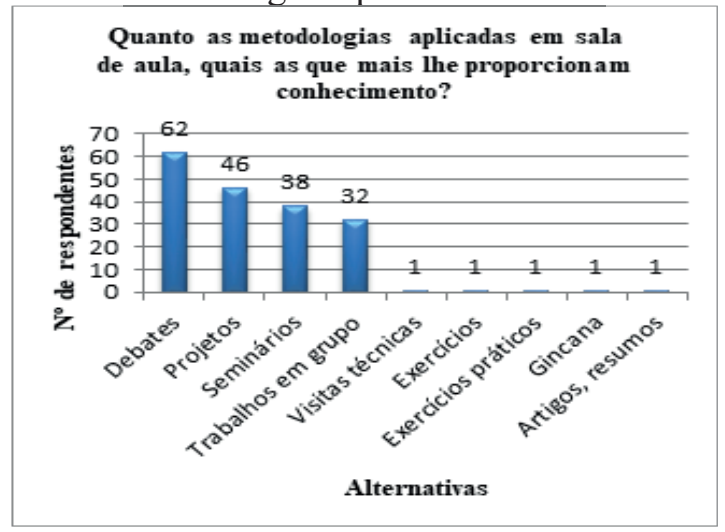

Fonte: elaborado pelos autores (2020).
No gráfico 5, buscou-se entender como os professores se sentem motivados para aplicar as metodologias ativas em suas aulas. Dez professores afirmaram que se sentem motivados quando há, na aula, alunos participativos - cor azul - representando $66,5 \%$. Seguindo dos 3 professores que afirmaram sentir motivação quando percebem que os alunos permanecem em sala de forma passiva - cor verde - representando $20,1 \%$. Houve um professor que afirmou se sentir motivado quando percebe que a turma está com o rendimento reduzido - cor vermelha - representando $6,7 \%$. Por último, houve 1 professor que não respondeu - cor lilás - representa $6,7 \%$. Nesta perspectiva, as turmas participativas acabam estimulando a criticidade, o pensamento próprio e o melhor posicionamento dos professores em sala de aula (MASETTO, 2009).

Gráfico 5 - Motivação ao aplicar metodologias ativas por parte dos docentes

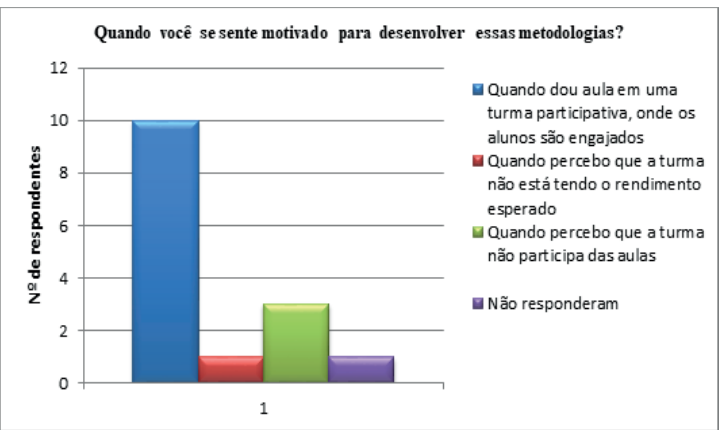

Fonte: elaborado pelos autores (2020).

No gráfico 6, buscou-se entender o nível de satisfação dos discentes quanto às metodologias aplicadas em aula pelos docentes, analisando a variação em 4 pontos: ótimo, bom, regular e ruim. Podemos observar que 56 estudantes marcaram a alternativa bom, correspondendo a $60,21 \%$. Seguido dos 22 estudantes que marcaram a alternativa regular, correspondendo a $23,65 \% ; 13$ estudantes marcaram a alternativa ótimo, correspondendo a $13,97 \%$; e 2 estudantes marcaram a alternativa ruim, correspondendo a $2,17 \%$. 
Com isso, vemos que a maior parte dos estudantes estão, pelo menos, parcialmente satisfeitos com as metodologias utilizadas. Entretanto, é necessário um olhar mais aprofundado nas técnicas discutidas por Ferrarini, Saheb, Torres (2019) sobre a Aprendizagem baseada em Problemas (ABP); Aprendizagem Baseada em Projetos (ABP); Aprendizagem Baseada em Games e Gamificação (GBL); Avaliação por Pares; e Sala de Aula Invertida, como mecanismos de estimular aprendizagem dos discentes que apontaram como "regular" e "ruim".

Gráfico 6 - Satisfação dos discentes quanto às metodologias aplicadas

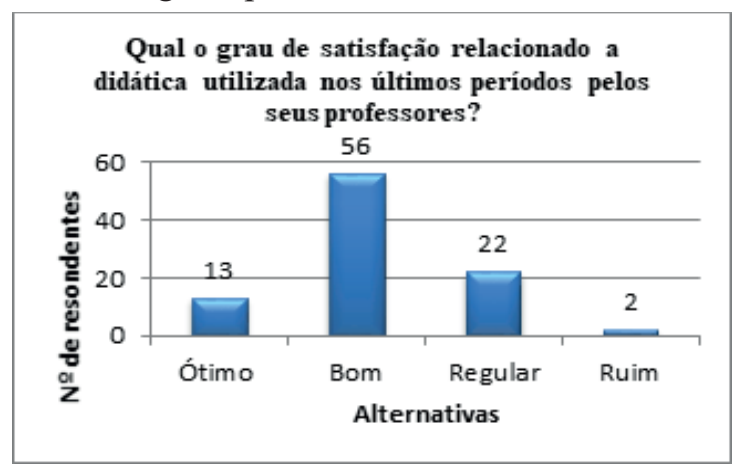

Fonte: elaborado pelos autores (2020).

No gráfico 7 , buscou-se entender se os professores estimulam as discussões sobre os assuntos em sala de aula, para manter o interesse dos estudantes e aumentar o nível de participação. Viu-se que 8 professores afirmaram gerar tais discussões e perceber a maior interação dos alunos - o que está expresso pela cor azul do gráfico, sendo a primeira barra apresentada no canto esquerdo - representa $53.3 \%$. Seguido dos 5 professores que afirmaram gerar tais discussões, embora percebam que não oferece o resultado esperado - cor vermelha - representa 33,3\%. Houve, também, um professor que afirmou dar aulas expositivas - cor azul - representando 6,7\%. Seguido de outro professor que afirmou fazer um misto de métodos tradicionais e atuais, embora não perceba interesse dos alunos, estando exposto na cor lilás, representando $6,7 \%$.
Gráfico 7 - Estímulo por parte da docência por meio das discussões em aul

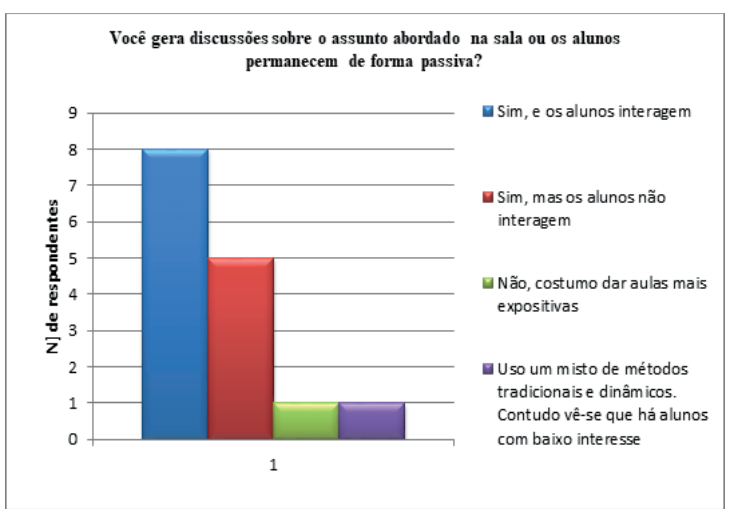

Fonte: elaborado pelos autores (2020).

No gráfico 8 , buscou-se identificar a visão dos discentes acerca da própria participação em sala. Podemos observar que 50 pessoas afirmaram ter participação parcial, o que corresponde a 53,76\%. Seguido dos 29 estudantes que afirmaram ser participativos, correspondendo a $31,18 \%$ e os 14 que afirmaram não ser participativos, correspondendo a $15,06 \%$. Com isso, vemos que a maior parte dos discentes têm consciência da falta de participação durante as aulas, o que se torna um dos fatores agravantes de baixo desempenho. Dificultando, assim, o desenvolvimento efetivo do ensino ativo discutido por Freire (1996) no qual tanto professores quanto alunos são transformados no processo de ensino e aprendizagem.

Gráfico 8 - Participação dos discentes nas aulas

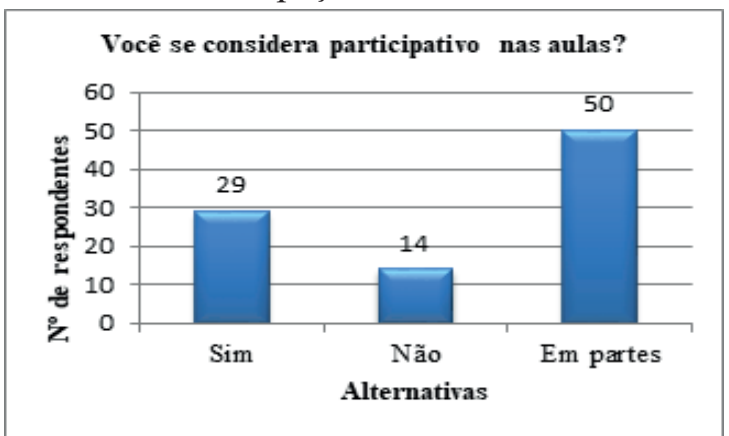

Fonte: elaborado pelos autores (2020).

O gráfico 9 apresenta a percepção dos discentes acerca das metodologias que melhor the proporcionam o aprendizado, lembrando 
que a pesquisa permitiu ao estudante escolher mais de uma alternativa. Podemos perceber que os debates ficaram à frente com 57 respondentes e $61,29 \%$. seguido das revisões com 52 marcações; $55,91 \%$; as explicações com 50 respondentes $53,63 \%$; a escrita com 44 respondentes $47,31 \%$; e os resumos com 34 respondentes e $36,55 \%$. O restante das alternativas teve somente uma marcação, sendo essas, fazendo exercícios, respondendo exercícios e elaborando mapa mental, correspondendo a $1,07 \%$. Com isso, vemos que a maior parte dos estudantes gostam de métodos que produzam explicações auditivas e visuais. Outro fator relevante são as múltiplas formas diferentes com que o indivíduo aprende, pois não é possível oferecer a mesma aula a todos, porque as pessoas aprendem em ritmos, tempos e formas diferentes (BACICH, 2018). Daí a importância das metodologias ativas.

Gráfico 9 - Melhor forma de aprendizado para os discentes

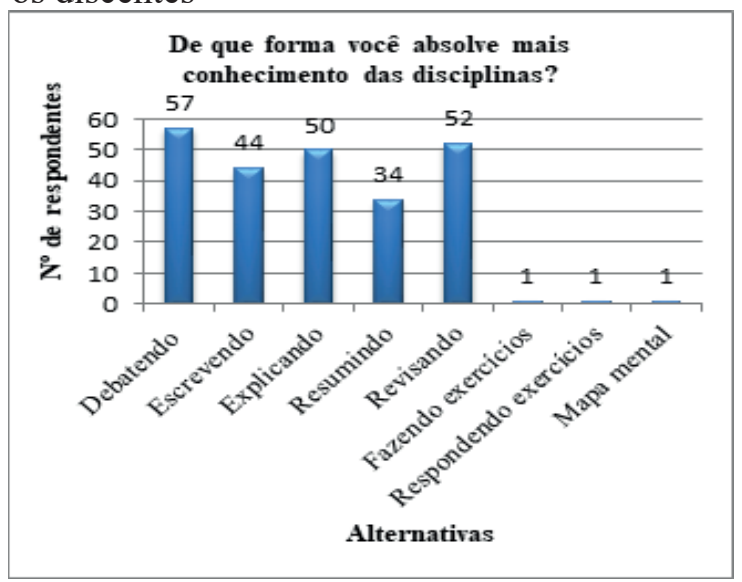

Fonte: elaborado pelos autores (2020).

No gráfico 10, buscou-se fazer uma varredura acerca da formação acadêmica dos docentes da UFRPE-UAST. Em face dos resultados, 9 professores possuem formação em Administração, sendo $60 \%$ do total, seguido dos cursos de Educação com 1 professor e 6,7\%; Matemática com 1 professor e 6,7\%; Administração e Economia com 1 professor e 6,7; Ciências Sociais com 1 professor e 6,7\%; Direito com 1 professor e $6,7 \%$ e Ciências da Computação com 1 profes- sor e $6,7 \%$. Houve, também, os cursos de Economia e Sistemas de Informação que ficaram sem nenhum respondente.

Gráfico 10 - Formação acadêmica dos docentes

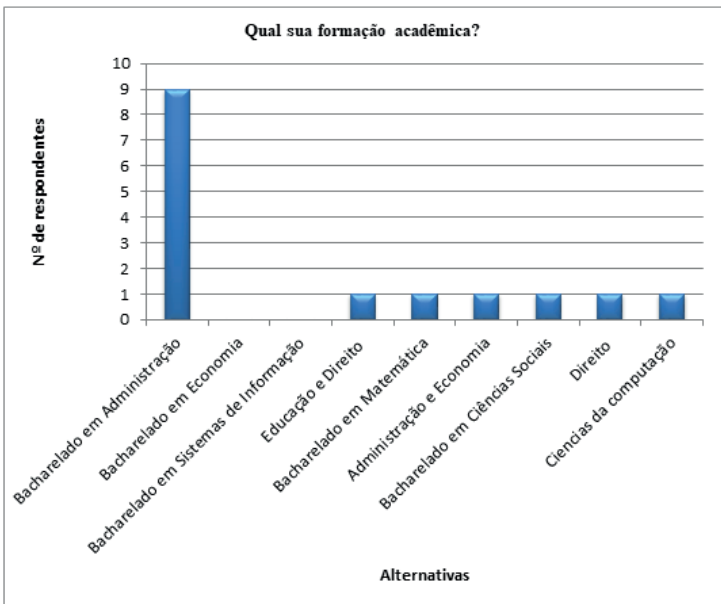

Fonte: elaborado pelos autores (2020).

No gráfico 11, buscou-se identificar o curso de graduação e a quantidade que os discentes estão cursando. Em face dos resultados, vimos que 66 estudantes pertencem ao curso de Administração, o que representa $71 \%$. Enquanto 27 estudantes são do curso de Economia, representando $29 \%$, sendo, no total, 93 discentes. Vale ressaltar que o número de discentes da instituição é bem maior no curso de Administração, com 271 alunos em julho de 2021.

No gráfico 12, buscou-se identificar a que período os discentes pertencem, tornando possível tornar visível o grau de experiência que os estudantes têm quanto às metodologias utilizadas no curso. A distribuição por período ficou da seguinte forma: 23 estudantes pertencem ao segundo período, o que corresponde a 24,73\%; quinto período com 13 respondentes e 14\%; primeiro período com 12 respondentes e $12,90 \%$; quarto período com 11 respondentes e $11,82 \%$; terceiro período com 8 respondentes e $8,60 \%$; sexto período com 7 respondentes e $7.52 \%$; sétimo com 6 respondentes e $6,45 \%$; oitavo período com 5 respondentes e 5,38\%; os alunos sem identificação que também tiveram 5 respondentes e 5,38\%; e, por fim, o nono período com 3 respondentes e $3,22 \%$. 
Gráfico 11 - Curso dos discentes

\section{Qual o seu curso?}

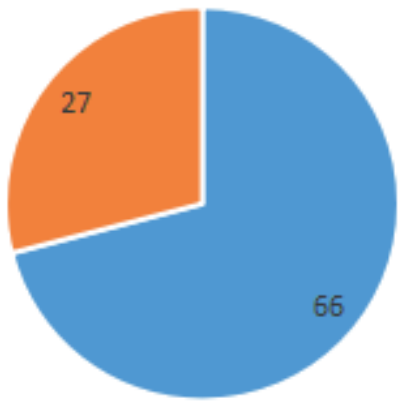

- Administração a Economia

Fonte: elaborado pelos autores (2020).

Gráfico 12 - Período dos discentes

\section{Qual o seu período corrente?}

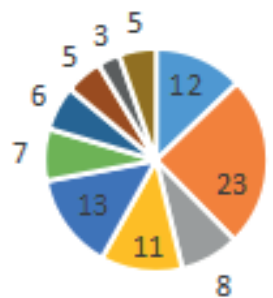

$$
\begin{aligned}
& \text { - } 1^{\circ} \text { período } \quad 2^{\circ} \text { período } \\
& \text { - } 3^{\circ} \text { período } \quad 4^{\circ} \text { período } \\
& \text { - } 5^{\circ} \text { periodo } \quad 6^{\circ} \text { período } \\
& \text { - } 7^{\circ} \text { período } \quad 8^{\circ} \text { período } \\
& \text { - } 9^{\circ} \text { periodo } \quad \text { Sem identificação }
\end{aligned}
$$

Fonte: elaborado pelos autores (2020).

Dessa forma, verificou-se que houve variação entre 2 e 19 anos de tempo de atuação como professor. Os fatores que motivam os professores a utilizarem as metodologias ativas são, respectivamente, melhor nível de aprendizagem dos discentes, maior interação e apreciação crítica; inovação; deixam as aulas mais participativas e menos monótonas; maior entendimento dos alunos e maior aproximação dos discentes com o conteúdo estudado.

Segundo Silva e Leonardo (2020), essa motivação ocorre para $71,4 \%$, quando eles dão aulas em turmas participativas em que os alunos são engajados; e, para $21,4 \%$, quando a turma não participa da forma esperada, permanecendo de forma passiva, pois é utilizado como forma de estimulá-los, e as disciplinas consideradas por $86,7 \%$ dos docentes, em que os discentes apresentam maiores dificuldades são as disciplinas de exatas.

As principais dificuldades encontradas pelos professores da UFRPE/UAST em relação ao aprendizado dos discentes são, respectivamente, prender a atenção dos alunos, ter dificuldade de intercalar o conteúdo com a prática, ensinar uma disciplina fora do eixo do curso e poder mencionar as disciplinas de instituições do direito e direito administrativo, visto que parte da dialética utilizada é pouco conhecida pelos estudantes, bem como a falta de interesse dos alunos nas aulas, a quantidade de alunos matriculados na disciplina, os alunos com baixo rendimento quanto à compreensão textual, $\mathrm{o}$ tempo de preparo das aulas e o pouco senso crítico-reflexivo; como também, Silva e Leonardo (2020) apontam, a falta de suporte da coordenação, pois 53,3\% afirmaram que não possuem suporte, e $46,7 \%$ afirmam que possui.

E os fatores que mais motivam os estudantes da UFRPE/UAST a participarem das aulas, são, respectivamente, dinâmicas em grupo. Tal prática proporciona maior interação e participação de todos os membros, bem como o esforço de alguns professores em buscar métodos diferenciados de ensino com uma abertura para debates, conhecimento, notas, possibilidades de mudar a vida financeira, após a formação acadêmica, exemplos reais, apresentação de seminários, mesas-redondas e uma formação acadêmica.

Os fatores que desmotivam são, respectivamente, aulas realizadas em slides, que são consideradas como uma das principais falta de interesse e defasagem de aprendizagem, metodologias arcaicas, obrigatoriedade de falar em grupo, falta de diálogo entre professores e alunos, falta de compreensão acerca da expli- 
cação, barulhos, excesso de conversas alheias à aula, assuntos que são de difícil compreensão e não há um tempo adequado para ser ensinado, arrogância de alguns professores, comentários desnecessários durante a explicação e cansaço por causa dos afazeres anteriores à aula; também existem estudantes que afirmaram ser incapazes de mencionar algo.

$\mathrm{E}$ as disciplinas em que os discentes apresentam grandes dificuldades são, majoritariamente, as exatas, como cálculo, macroeconomia, microeconomia, análise de custos e balanços, estatística e matemática financeira; quanto às disciplinas que fogem desse perfil, formas mencionadas gestão de pessoas, processo decisório, instituições do direito, direito administrativo, português e metodologia científica. Também houve aqueles que afirmaram não ter dificuldade em nenhuma disciplina.

Quanto às sugestões de melhorias apontadas pelos discentes, vimos que alguns estudantes mencionaram a criação de mapas mentais, em troca dos slides, outros pontos foram o aumento dos debates, aulas práticas, exemplos reais do dia a dia, incentivo da ideia de aluno-pesquisador, melhor interação entre discente e docente, professores que levam em consideração o perfil do aluno, PCD bilateral auditivo, apresentação de assuntos mais atuais, exercícios, projetos e explicações mais simples. Em síntese, vemos que os estudantes da UFRPE-UAST apresentam desinteresse pelos métodos tradicionais de ensino.

\section{CONSIDERAÇÕES FINAIS}

A fim de responder ao problema de pesquisa, o estudo evidenciou que, em sua maioria, os professores são formados em administração, com um quadro de contribuições bem amplo, entre 2 a 19 anos, em que 93,3\% afirmam que conhecem e $86,7 \%$ já utilizam as metodologias ativas em suas aulas. Isso proporciona e corrobora as metodologias utilizadas em seus planos de aula bem abrangentes, pois a sua maioria busca interagir e estimular por meio de métodos que proporcionem o protagonismo do estudante na formação do conhecimento coletivo, tendo os estudos dirigidos em grupo e sala de aula invertida mediante seminários e debates como os mais citados. Como principal desafio, $40 \%$ afirmam a falta de entendimento de alguns discentes sobre essas novas metodologias de ensino.

Em relação aos discentes, o estudo evidenciou que a maioria dos respondentes também são do curso de Administração de todos os períodos, sendo $24,73 \%$ do segundo período seguido do quinto período com $14 \%$. Além disso, majoritariamente, buscam interagir com métodos que proporcionem o protagonismo individual e coletivo, evidenciando trabalhos e projetos em grupo, seminários e debates como os métodos preferidos; além disso, um pouco mais da metade afirma conhecer as metodologias ativas e mostra-se satisfeita com os métodos utilizados por seus professores em aula e considera-se participativa nas aulas. Como principal desafio, foram mencionadas a resistência de alguns professores em utilizar metodologias arcaicas, a falta de abertura ao diálogo e aulas pautadas em apenas leituras de slides, que se mostram como os principais fatores que promovem a falta de interesse nas aulas.

Assim, é importante ressaltar que este artigo apresenta algumas limitações no decorrer da pesquisa e no corte do estudo. Inicialmente, a delimitação da pesquisa ocorre atrás da quantidade de cursos, pois aprecia apenas dois cursos da unidade, visto que a quantidade de respondentes é inferior ao total de docentes do quadro, além da quantidade de discentes que, também, é inferior ao total de alunos dos dois cursos aqui estudados.

Portanto, a pesquisa também pode sugerir novos estudos mais detalhados, ampliando para outros cursos da UFRPE/UAST e outras instituições de ensino, bem como definir outros objetivos dentro da temática das metodologias ativas. Ademais, sugerem-se novos estudos acerca da aplicação e adaptação do ensino remoto com auxílio das tecnologias.

As implicações dos resultados deste estudo no conjunto de estudos sobre as metodologias ativas puderam proporcionar um espaço de 
aplicação de teorias e entendimento na prática de como os atores envolvidos percebem e dinamizam esses métodos de aprendizagem que estão ligados, fortemente, com o desempenho da instituição e dos seus. Outrossim, o estudo causa um impacto nos cursos de Administração e Economia, como forma de observar a atuação docente e os anseios do corpo discente perante o ensino. Ainda mais, contribui com a literatura acerca das metodologias ativas aplicadas ao ensino superior.

\section{REFERÊNCIAS}

BACICH, L. Crescer em redes: inovações na prática pedagógica: formação continuada de professores para competências de ensino no século XXI. São Paulo: Instituto Crescer, 2018.

BATES, A. W. T. Educar na era digital: design, ensino e aprendizagem. São Paulo, Artesanato Educacional, 2017.

DZIEKANIAK, G.; ROVER, A. Sociedade do conhecimento: características, demandas e requisitos. Pesquisa Brasileira em ciência da informação e biblioteconomia, v. 7, n. 1, 2013. Disponível em: https://periodicos.ufpb. br/ojs/index.php/pbcib/article/view/14246. Acesso em: 7 nov. 2020.

FERRARINI, R.; SAHEB, D.; TORRES, P. L. Metodologias ativas e tecnologias digitais: aproximações e distinções. Revista Educação em Questão, Natal, v. 57, n. 52, p. 1-30, e- 15762, abr./jun. 2019.

FREIRE, P. Pedagogia do oprimido. São Paulo: Editora Paz e Terra, 1996.

GIL, A. C. Como elaborar projetos de pesquisa. 5. ed. São Paulo: Atlas, 2010.

LOBO, A. S. M.; MAIA, L. C. G. O uso das TICs como ferramenta de ensino-aprendizagem no Ensino Superior. UFMG: Caderno de Geografia, v. 25, n. 44, 2015. Disponível em: http:// www.luizmaia.com.br/docs/cad geografia tecnologia_ensino.pdf. Acesso em: 18 ago. $20 \overline{2} 0$.
MASETTO, M. T. Formação pedagógica dos docentes do ensino superior. Revista Brasileira de Docência, Ensino e Pesquisa em Administração, v. 1, n. 2, p. 4-25, jul. 2009.

MASETTO, M. T. Inovação na Educação Superior. Interface: Comunic., Saúde, Educ., v. 8, n. 14, p. 197-202, set. 2003, fev. 2004. Disponível em: https://www.scielo.br/pdf/icse/ v8n14/v8n14a17.pdf. Acesso em: 18 ago. 2020.

MORAN, J. M. Internet no ensino universitário: pesquisa e comunicação na sala de aula. São Paulo: USP, 1998. Disponível em: https:// www.scielo.br/pdf/icse/v2n3/10.pdf. Acesso em: 18 ago. 2020.

OLIVEIRA, M. F. Metodologia científica: um manual para a realização de pesquisas em Administração. Catalão: UFG, 2011.

PEREIRA, T. A. Metodologias ativas de aprendizagem do século XXI: integração das tecnologias educacionais. São Paulo: USP, 2017.

PIOVESAN, A.; TEMPORINI, E. R. Pesquisa exploratória: procedimento metodológico para estudo de fatores humanos no campo da saúde pública. Revista de Saúde Pública USP, p. 318-325, 1995. Disponível em: https://www. scielo.br/pdf/rsp/v29n4/10.pdf. Acesso em: 7 nov. 2020.

REIS, E. A.; REIS, I. A. Análise descritiva de dados. UFMG, Instituto de Ciências Exatas Departamento de Estatística, junho de 2002.

RICHARDSON, R. J. Pesquisa social: métodos e técnicas. 3. ed. São Paulo: Atlas, 2012.

SILVA, M. R. de A.; LEONARDO, J. A. C. Percepção dos docentes de administração e economia da UAST/UFRPE sobre metodologias ativas. In: FARIAS, Ana Paula da Silva; FERREIRA, Renan Silva; BRANDÃO, Suiane Valença (org.). Ebook Abordagens contemporâneas da Administração: o poder da teoria em prática. Serra Talhada, PE: Even3, 2020. p. 141 a 156. Disponível em: https://even3.blob. 
core.windows.net/even3publicacoes-assets/ book/512978-abordagens-contemporaneas-da-administracao-o-poder-da-teoria.pdf. Acesso em: 8 nov. 2020.

VALENTE, J. A. Blended learning e as mudanças no ensino superior: a proposta da sala de aula invertida. Educar em Revista, Curitiba, n. 4, p. 79-97, 2014. Disponível em: https:// www.scielo.br/pdf/er/nspe4/0101-4358-er-esp-04-00079.pdf. Acesso em: 19 ago. 2020.

YIN, R. K. Estudo de caso: planejamento e métodos. Porto Alegre, RS: Bookman, 2005. 